\title{
Numb chin: A simple sign of a catastrophic illness
}

\author{
Catarina R. Oliveira*1, Ana C. Cabral ${ }^{1}$, Ana P. Oliveira ${ }^{1}$, Maria I. Seixas ${ }^{2}$, Rui André ${ }^{3}$, Cláudia Martins ${ }^{4}$, Jorge M. \\ Correia $^{4}$, Luís Costa-Matos ${ }^{5,6}$, A. Monteiro ${ }^{7}$ \\ ${ }^{1}$ Internal Medicine Resident, Centro Hospitalar Tondela-Viseu, Portugal \\ ${ }^{2}$ Rheumatology Resident, Centro Hospitalar Tondela-Viseu, Portugal \\ ${ }^{3}$ Neurologist Attendant, Centro Hospitalar Tondela-Viseu, Portugal \\ ${ }^{4}$ Internal Medicine Attendant, Centro Hospitalar Tondela-Viseu, Portugal \\ ${ }^{5}$ Internal Medicine Graduate Attendant, Centro Hospitalar Tondela-Viseu, Portugal \\ ${ }^{6}$ Faculty of Health Sciences, Beira Interior University, Portugal \\ ${ }^{7}$ Internal Medicine Senior Attendant, Centro Hospitalar Tondela-Viseu, Portugal
}

Received: September 30, 2015

Accepted: November 12, 2015

Online Published: December 2, 2015

DOI: $10.5430 /$ crim.v3n1p21

URL: http://dx.doi.org/10.5430/crim.v3n1p21

\begin{abstract}
The sensory neuropathy of the mental nerve (Numb Chin Syndrome-NCS) is a rare neurological condition which is often associated with malignancy, as a sentinel clinical presentation. The most common primary tumours related to it are lymphoma and breast cancer. In the clinical case presented, the patient in question had no previous neoplastic history and it was due to this symptom that the investigation was carried out. Therefore, with this research, it is intended to create awareness to the fact that while in most cases NCS can be underestimated, it is a sign that can be extremely important and in fact reveal a hidden tumour. The case is of utter importance because early recognition of this type of signs are fundamental for timely diagnosis and treatment impacting on the patient's outcome.
\end{abstract}

Key Words: Numb chin syndrome, Malignancy, Primary tumour, Metastasis

\section{INTRODUCTION}

Neuropathy, a result of the damage of the nerves, often causes weakness, numbness and pain, in the affected nerve. This damage can be a result of traumatic injuries, infections, metabolic problems, inherited causes, tumours and exposure to toxins. ${ }^{[1-9]}$ The cranial nerves are those that arise directly from the brain or brainstem and often affect areas such as the face and eyes. The sensory neuropathy of the mental nerve (Numb Chin Syndrome-NCS) is a rare neurological condition, often associated with malignancy, as a sentinel clinical presentation. ${ }^{[1-13]}$ The most common primary tumours related to it are lymphoma and breast cancer. ${ }^{[7]}$ There are reported cases where there were no history of tumours and it was due to the onset of this symptom that the investigation commenced was conducted. ${ }^{[3,8,11-13]}$ Therefore, the NCS is a sign that can be extremely important and reveal a hidden tumour and this research should begin using the many complementary diagnostic tests that are available today, because early recognition can have an impact on patient's quality of life. ${ }^{[6,8,11,12]}$

\section{CASE REPort}

A 61-year-old caucasian male, showed signs of pruritic skin lesions with about two weeks of evolution, identified as sar-

*Correspondence: Catarina R. Oliveira; Email: catarina.andreia @gmail.com; Address: Centro Hospitalar Tondela-Viseu, Quinta da Ramalhosa, Lote $14,2^{\circ}$ Dto. Frente. 3510-141 Viseu, Portugal. 
coptosis. Additionally, the patient presented himself as very anxious and reported a history of tactile hypoesthesia of the left side of the chin. The patient denied pain or paresthesia in that region and there was no history of dental abscesses, anesthesia nor local trauma or other symptoms associated. The patient's background included a total of 43 pack years of heavy smoking, hypertension, chronic laryngitis and dyslipidemia, and was currently on losartan $100 \mathrm{mg}$ od, indapamide $2.5 \mathrm{mg}$ od, lercanidipine $10 \mathrm{mg}$ od and fenofibrate $267 \mathrm{mg}$ od. Physical examination showed that the patient was afebrile with stable vital signs. He was observed by a neurologist and no additional focal neurologic signs were detectable, apart from the hypoesthesia of the patient's lower left chin. An $\mathrm{X}$-ray and a computed tomography (CT) of the skull were requested and the results were normal. Since the hypothesis of it being a numb chin syndrome was questioned, the patient was discharged while results were still pending for diagnostic laboratory tests, namely a Magnetic Resonance Imaging (MRI) of the brain, an electromyography and a CT scan of the thorax, abdomen and pelvis. The patient returned to the emergency room nearly two weeks later, complaining of pain in the upper right quadrant and epigastrium as well as abdominal distention, anorexia, postprandial fullness, with weight loss of about $10 \mathrm{~kg}$, asthenia and an infrequent cough. A chest X-ray revealed upper mediastinal enlargement and an abdominal ultrasound showed "liver riddled with metastasis" (see Figure 1). Laboratory testing revealed anaemia (Hb:13.6 $\mathrm{g} / \mathrm{dl}$ ) and thrombocytopenia (platelet: $62 \mathrm{~K} / \mathrm{ul}$ ), in which the serum lactic dehydrogenase level was $1648 \mathrm{mg} / \mathrm{dl}$, C-reactive protein was $5.79 \mathrm{mg} / \mathrm{dl}$ and liver enzymes were high, with aspartate transaminase of $112 \mathrm{U} / \mathrm{L}$ and alanine transaminase of $129 \mathrm{U} / \mathrm{L}$. The patient was hospitalised for a clarification of the diagnosis. The CT scan of the thorax, abdomen and pelvis (with intravenous contrast) showed "lung parenchyma with multiple nodules and some rounded and poorly defined infiltrates, suspicious of secondary lesions, multiple adenopathies mostly in the upper mediastinum, forming a mass / conglomerate of adenopathies (see Figure 2) of $8 \mathrm{~cm}$ in diameter, compressing the superior vena cava (SVC). Liver size was larger with multiple nodules suggestive of massive metastasis (see Figure 3)". On the ninth day of hospitalisation, a stent was placed in the SVC. However, the clinical status continued to worsen. Three days later, while waiting for the biopsy of lesions, the patient showed signs of severe respiratory failure, respiratory acidosis, and despite of all medical procedures and non-invasive ventilation therapy, the patient died.

\section{Discussion}

NCS is an unusual sensory neuropathy characterised by the numbness, hypoesthesia, paraesthesia or pain (less common) of the chin and lower lip caused by a dysfunction of the mental nerve. ${ }^{[1-10]}$ This is one of the terminal branches of the mandibular division of the trigeminal nerve. ${ }^{[11]}$ The mental nerve is responsible for supplying the skin of the chin and lower lip and the mucous membranes on the buccal surface of the lower lip. ${ }^{[1,12]}$ Many processes can cause a lesion of the mental nerve, and consequently sensory loss or pain, by direct compression of the mental nerve by tumour mass, leptomeningeal invasion or a lesion at the mental foramen. ${ }^{[1,3,11]}$

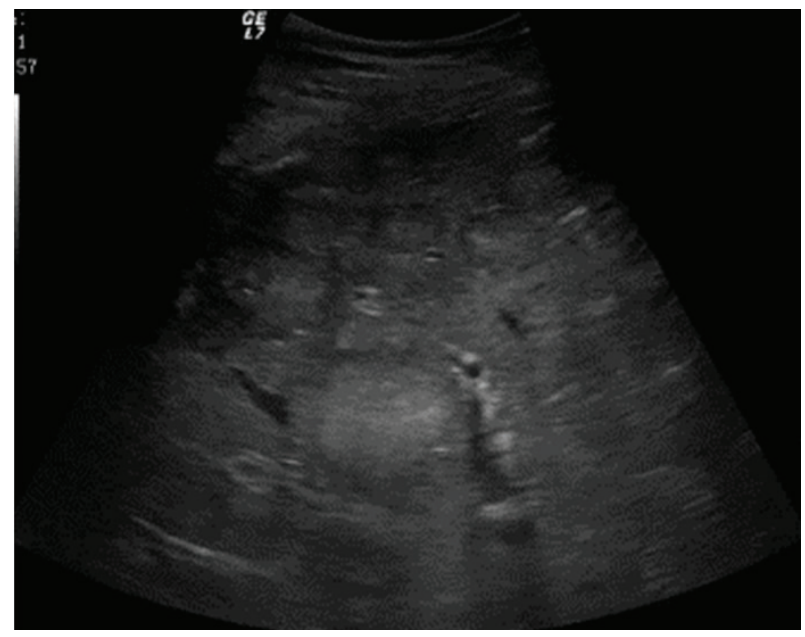

Figure 1. Abdominal ultrasound showing liver riddled with metastasis

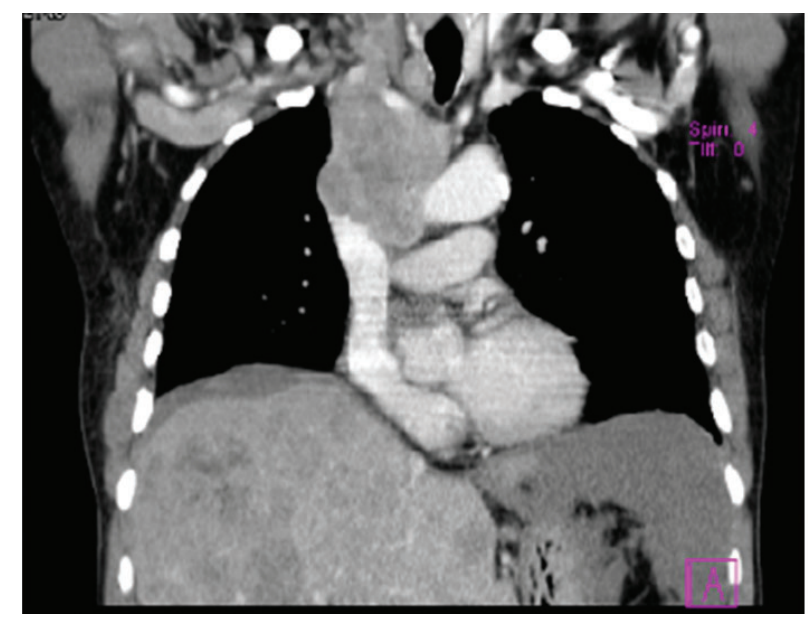

Figure 2. CT scan of the thorax revealing multiple adenopathies in the upper mediastinum, forming a mass/conglomerate that compresses the superior vena cava

NCS can be a sign of tumour progression, the first symptom of malignancy (a "red flag" symptom) or it can be due to benign causes (which is less common). ${ }^{[4,6,8,9]}$ Dental procedures or infections, mandibular cysts, trauma, systemic diseases such amyloidosis, sickle cell anaemia, sarcoidosis, 
multiple sclerosis, HIV, diabetes mellitus and malignant neoplasms are etiologic factors for this rare syndrome. ${ }^{[1-5,7,9-13]}$ Various malignant and metastatic neoplasm are involved in the onset of this syndrome. ${ }^{[7]}$ Those, have most often been related to metastatic breast cancer, thyroid cancer and lymphoproliferative processes, such as lymphoma, the first two, representing the majority. ${ }^{[7]}$ However, other cases of prostatic carcinoma, colon, lung and kidney tumours have been described. ${ }^{[2,7]}$

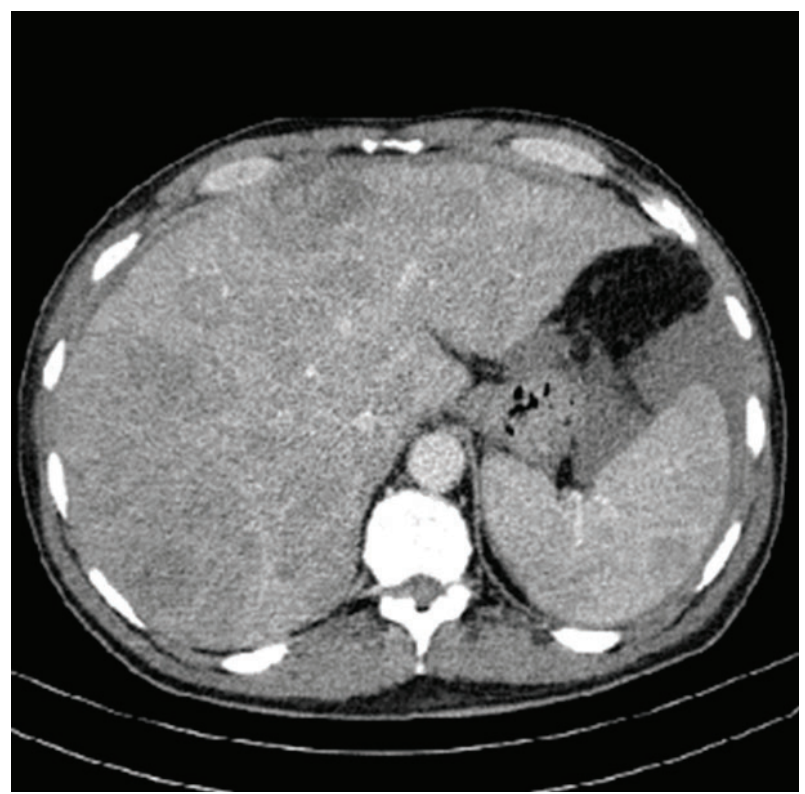

Figure 3. Abdominal CT scan showing a large liver with multiple nodules suggestive of massive metastasis

The real incidence of NCS is still unknown because many cases are undiagnosed. ${ }^{[2]}$ The diagnosis of NCS should be clinical, supported by suitable laboratory and radiologic studies. ${ }^{[2,8,10]}$ Clinicians should be aware of the trivial symptom because it may be a sign of a serious pathology and thus its importance. ${ }^{[9]}$ One of the most important aspects of the diagnosis of this neuropathy is the number of cases in which it can be the first symptom of an undiagnosed underlying cancer in a significant proportion of cases (up to $47 \%$ of patients). For example, as in the presented case, supporting the concept that malignant aetiologies should be considered, until proven otherwise, in patients who have this syndrome..$^{[3,8,11,12]}$ This illustrates the importance of a good medical history and physical exam. For early diagnosis optimal clinical examination and appropriate radiological investigation is needed to locate the lesion to then initiate a treatment. ${ }^{[8]}$

Panoramic radiography of the jaw can offer valuable information and further details can be obtained through CT imaging of the skull. ${ }^{[6]}$ When these two forms of imaging do not provide the necessary information, the use of an MRI is suggested. ${ }^{[6,10]}$ In the case presented imaging did not reveal any evidence of mandibular metastasis or involvement of the base of the skull, but unfortunately the patient did not make it in time to carry out the MRI. It is worth mentioning that lack of radiographic changes cannot exclude the possibility of small metastatic lesions in the jaw that may go unnoticed in imaging exams. ${ }^{[6]}$ A lumbar puncture and cytological analysis of cerebrospinal fluid can be useful, predominantly in cases where radiography is negative. ${ }^{[1]}$

The prognosis of patients with NCS as a result of malignancy is very poor with a calculated survival span of just months, and the management is usually palliative. ${ }^{[6,8,12]}$ Thus, early recognition does not have an impact on overall survival, but it is known that local radiotherapy can provide effective palliation in patients with a poor prognosis. Therefore, the early appreciation of such sign can help the patients in a palliative perspective, controlling the pain and the impairment of mastication and improving the patient's quality of life. ${ }^{[8,13]}$

In this particular case, the patient passed away within a few weeks and there was no accurate diagnosis. Nonetheless, all the findings indicate lung cancer, which is according to literature, as being one of the tumours that metastasizes to the jaw.

\section{REFERENCES}

[1] Baskaran RK, Krishnamoorthy SM. Numb chin syndrome-a reflection of systemic malignancy. World J Surg Oncol. 2006; 4: 52. http://dx.doi.org/10.1186/1477-7819-4-52

[2] Liapis K, Apostolidis I, Karmiris T, et al. Numb chin syndrome as the initial manifestation of acute megakaryoblastic leukemia. Leukemia \& Lymphoma. 2010; 51(12): 2310-2311. http://dx.doi.org/1 $0.3109 / 10428194.2010 .520776$

[3] Fan Y, Luka R, Noronha A. Non-Hodgkin lymphoma presenting with num chin syndrome. BMJ Case Rep. 2011. http://dx . doi .org/1 $0.1136 /$ bcr. 01.2011 .3712

Published by Sciedu Press
[4] Cavallito C, Ferrera FD, Arduino PG, et al. Numb chin syndrome. Ann Stomatol. 2013; Suppl. 2: 1-48.

[5] Ichikawa S, Saito K, Suzuki T, et al. Primary Retroperitoneal Diffuse Large B-cell Lymphoma presenting with Numb Chin Syndrome and Painful Ophtalmoplegia. Intern Med. 2013; 52: 1813-1819. http://dx.doi.org/10.2169/internalmedicine.52.0604

[6] Zaheer F, Hussain K, Rao J, et al. Unusual presentation of numb chin syndrome as the manifestation of metastatic adenocarcinoma of the lung. Int J Surg Case Rep. 2013; 4: 1097-1099. http: //dx.doi.org/10.1016/j.ijscr.2013.08.024

[7] Elahi F, Luke W, Elahi F. Intractable facial pain and numb chin due 
to metastatic esophageal adenocarcinoma. Case Rep Oncol. 2014; 7 : 828-832. http://dx.doi.org/10.1159/000369785

[8] Tejani N, Cooper A, Rezo A, et al. Numb chin syndrome: A case series of a clinical syndrome associated with malignancy. J Med Imaging Radiat Oncol. 2014; 58: 700-5. http://dx.doi.org/10. $1111 / 1754-9485.12177$

[9] Riesgo VJ, Delgado SR, Poveda J, et al. Num chin syndrome secondary to leptomeningeal carcinomatosis from gastric adenocarcinoma. J Gastrointest Oncol. 2015; 6: E16-E20. http://dx.doi.o $\mathrm{rg} / 10.3978 / \mathrm{j}$. issn. 2078-6891.2014.076

[10] Carbone M, Ferrera FD, Carbone L, et al. Numb Chin Syndrome as first symptom of diffuse large B-cell lymphoma. Case Rep Dent. 2014. http://dx.doi.org/10.1155/2014/413162

[11] Harris CP, Baringer JR. The numb chin in metastatic cancer. West J Med. 1991; 155: 528-31. PMid:1815405

[12] Evans RW, Kirby S, Purdy RA. Numb Chin Syndrome. Headache. 2008; 48: 1520-1524. http://dx.doi.org/10.1111/j.1526-4 $610.2008 .01302 \cdot \mathrm{x}$

[13] Aksoy S, Orhan K, Kursun S, et al. Metastasis of prostate carcinoma in the mandible manifesting as num chin syndrome. World J of Surg Oncol. 2014; 12: 401. http://dx.doi.org/10.1186/1477-781 9-12-401 